\title{
Liver Cancer
}

Consolato M. Sergi, MD, PhD, MPH, FRCPC, FCAP

Editor

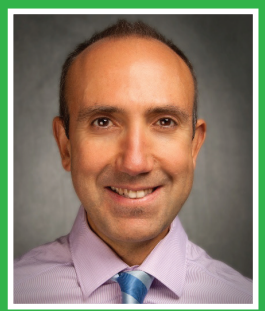

Consolato M. Sergi, MD, PhD, MPH, FRCPC, FCAP, is a full professor of pathology and adjunct professor of pediatrics at the University of Alberta, Edmonton, Canada. He is also a consultant for Standards and Guidelines in Carcinogenesis of Chemical Compounds published by the World Health Organization/International Agency on Research on Cancer (WHO/IARC monographs), Lyon, France. His research interests include hepatic tumors, metabolic diseases, cholangiopathies, organ transplantation, and gut/bile microbiome using cell lines, animal models, and clinical samples. He identified the role of apoptosis in ductal plate malformation of the liver, characterized sialidosis, and found two new genes, WDR62, which encodes a centrosome-associated protein (Nat Genet 2010) and OTX2, mutations of which can contribute to dysgnathia (J Med Genet 2012). Professor Sergi has published more than 300 research/ review articles and several books and book chapters. He has supervised and mentored many PhD students and clinical fellows. He is also on the editorial boards of several scientific journals.
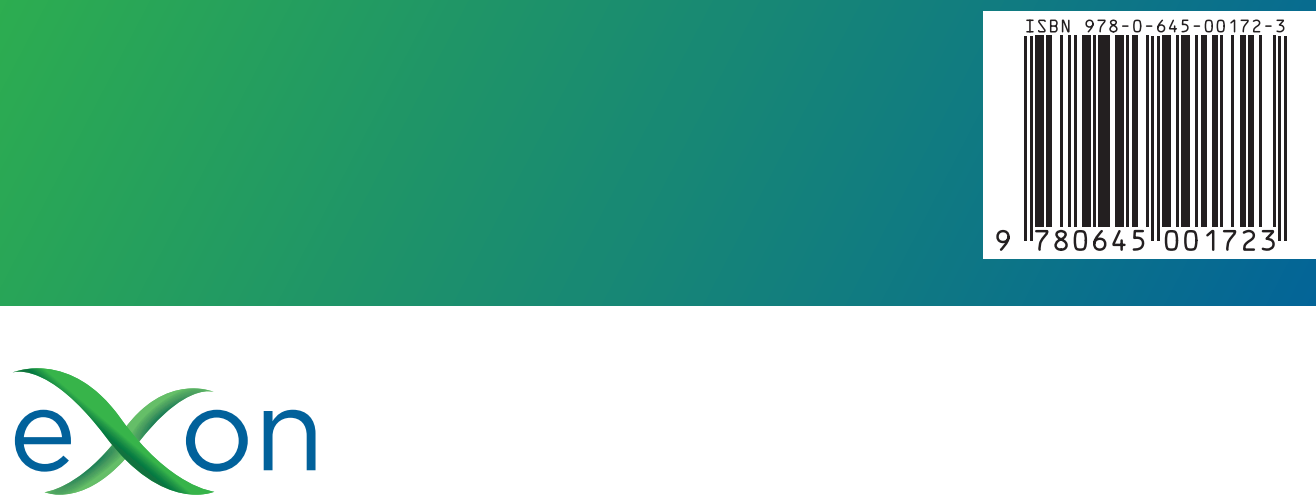

$P \cup B L I C A T I O N S$ 